\title{
Problem of nosocomial infection with Hepatitis B, $C$ viruses and HIV in Russian dental institutes: review
}

Alexey Shatokhin

From $16^{\text {th }}$ International Symposium on HIV and Emerging Infectious Diseases

Marseille, France. 24-26 March 2010

\section{Background}

The problem of nosocomial infection with hepatitis B, C viruses and HIV is important for the Russian Dental Health Service. It is connected with the unfavourable epidemic situation in respect of these viral infections, limited availability of dental safe technologies (DST), means of postcontact prevention etc. in public dental practice.

The purpose of the review is the problem reflection of nosocomial HIV \& Viral hepatitis infection for dental service in scientific domestic publications.

\section{Methods}

The review of the scientific literature on this problem for last 5 years.

\section{Results}

According to Platoshina O. et al (2004), among patients of the health care institutions in Saint-Petersburg (S.-Pb.) carriers of HBV and $\mathrm{HCV}$ are 3-7 times more frequent, than in the general population. Their longitudinal three-year survey detected $56.6 \%$ a prevalence of hepatitis B virus antigen (HBsAg) among the dental staff in $\mathrm{S} .-\mathrm{Pb}$. Interrogation of $\mathrm{S} . \mathrm{-Pb}$. medical persons has shown that $24 \%$ do not use the safety equipment (SE). In other survey the surgeons-dentists at municipal clinics in $\mathrm{S}$.- $\mathrm{Pb}$. reported regularly changing gloves in only $36.7 \%$ of cases, and $63.3 \%$ of applied antiseptic to the gloves without changing them after the treatment. This is perhaps accounted for by the insufficient provision within municipal medical institutions of SE.
A high prevalence of HIV-infection has been observed in Moscow during the latest decade. Based on those general population statistics, the Probability of Infection (PI) of a dentist with HIV in Moscow would be 0.000013 , while in providing dental aid to Injection Drug Users, the PI wouldbe 0.00078 , which is $\mathbf{6 0}$ times higher. Retrospective epidemiological analysis in Moscow shows that the PI of the dentist for HIV has increased during 10 years (1995-2005) as much as 65 times [Goliusov A., 2008].

\section{Discussion}

Considering current conditions concerning viral hepatitis and HIV-infection in Russia, it is important to develop in dental personnel a better understanding of the potential risks, mechanisms of infection with bloodborne viruses and to draw up protocols with precise information about various occupational exposures. This should be enhanced by regular training on the use of DST for all members of the dental team.

Published: 11 May 2010

doi:10.1186/1742-4690-7-S1-P133

Cite this article as: Shatokhin: Problem of nosocomial infection with Hepatitis B, C viruses and HIV in Russian dental institutes: review. Retrovirology 2010 7(Suppl 1):P133.

Correspondence: sha_tai@hotmail.com

City AIDS Center, Moscow, Russian Federation 